\title{
Sudden Death in Sports: Case Report and Review of an Ongoing Problem
}

\author{
María Elena Caparrós-Hernández¹, Mónica García-Fernández¹, Carla Miró-Vicedo¹, \\ María del Mar Ponce-Abellán', Andrea Ruso-Ruso1, María Dolores Jover-Ríos², \\ Juan Méndez-Mora ${ }^{3}$, Francisco Caparrós-Hernández ${ }^{3}$, Carmen Seguí-Pérez ${ }^{3}$, Marc Seguí-Pérez ${ }^{3}$, \\ Pedro Esteve-Atiénzar4, Jorge Peris-García 4,5, David Bonet-Tur ${ }^{4}$, Pablo Roig-Rico 4,5, \\ Asunción Pérez-Fullana3 ${ }^{3}$, José Miguel Seguí-Ripoll4,5*
}

\author{
${ }^{1}$ School of Medicine, Miguel Hernández University, Elche (Alicante), Spain \\ ${ }^{2}$ Department of Internal Medicine, Hospital La Vega Baja of Orihuela (Alicante), Spain \\ ${ }^{3}$ Secondary School, Marist Brothers High School, Alicante, Spain \\ ${ }^{4}$ Department of Internal Medicine, University Hospital of San Juan, Alicante, Spain \\ ${ }^{5}$ Department of Clinical Medicine, Miguel Hernández University, Elche (Alicante), Spain \\ Email: *jsegui@umh.es
}

How to cite this paper: CaparrósHernández, M.E., García-Fernández, M., Miró-Vicedo, C., del Mar Ponce-Abellán, M., Ruso-Ruso, A., Jover-Ríos, M.D., MéndezMora, J., Caparrós-Hernández, F., SeguíPérez, C., Seguí-Pérez, M., Esteve-Atiénzar, P., Peris-García, J., Bonet-Tur, D., RoigRico, P., Pérez-Fullana, A. and Seguí-Ripoll, J.M. (2019) Sudden Death in Sports: Case Report and Review of an Ongoing Problem. Health, 11, 67-80.

https://doi.org/10.4236/health.2019.111008

Received: December 22, 2018

Accepted: January 27, 2019

Published: January 30, 2019

Copyright $\odot 2019$ by author(s) and Scientific Research Publishing Inc. This work is licensed under the Creative Commons Attribution International License (CC BY 4.0).

http://creativecommons.org/licenses/by/4.0/

\begin{abstract}
Background: Both competitive and recreational sports are considered a positive practice that is good for human health and quality of life, so it is difficult to understand how young, energetic and apparently healthy people can die while playing their usual sports. When these events occur in elite athletes during monitored events, they normally receive considerable media attention. Objective: To describe the case of sudden death in a young professional athlete who was successfully aided and resuscitated outside our hospital, and to review the literature about sudden death in sports. Materials and Method: We searched for Sudden Death (according to the International Classification of Diseases (ICD-9 and ICD-10)) in our hospital but found no other relevant cases. We performed a literature search on the state of the art in sudden death (Google Scholar, PubMed, LILACS, Scielo and the Revista Española de Cardiología). Results: Although we observed that the prevalence of sudden death is not very high, it still represents a potentially avoidable event. An adequate medical examination prior to regular sporting practice can decrease the incidence of sudden death in athletes under the age of 35. Data available in the literature support medical check-ups that include history-taking, physical examination and electrocardiogram. The findings of this evaluation may also prompt further assessment (electrocardiograph, ergometry). Conclusions: We could not identify standard, obligatory guidelines for screening possible heart diseases causing cardiorespiratory failure and sudden death. As a meas-
\end{abstract}


ure for primary prevention, we propose a protocol for reducing the risk of sudden death in athletes.

\section{Keywords}

Sudden Death, Sports, Athletes, Cardiopulmonary Resuscitation, Implantable Automatic Defibrillator

\section{Introduction}

Sudden death (SD) is defined as an unexpected fatal event that occurs in an apparently healthy person. It is quite rare in people under the age of 35 , and its importance is relative given the low prevalence. Nevertheless, these deaths in young people are very jarring for the population at large. Thus, it is necessary to invest sufficient resources to address the problem through a multidisciplinary approach, identifying individuals at high risk who may benefit from preventive treatment strategies [1].

The relationship between SD and sports is time-bound, as most of these events occur during or immediately after training or competition. These cases consistently make headlines in sports media, generating uncertainty in this community, as it is difficult to understand how young, energetic and apparently healthy people can die while playing their usual sports. Cardiovascular diseases are the most frequent cause of SD (both in athletes and in the general, non-athletic population). Among young, fit athletes with adequate training, diverse cardiovascular diseases have been identified as the cause of SD, including atheromatous heart disease, arrhythmogenic cardiomyopathy (AC), myocardial fibrosis, hypertrophic cardiomyopathy, idiopathic left ventricular hypertrophy (LVH), aortic valve disease, anomalies of the coronary arteries, and vascular pathologies. Depending on the case series and country, there is some etiological variation. Thus, a standardized and straightforward screening protocol should be implemented in order to identify (or at least raise the suspicion of) potentially risky cardiovascular diseases [2].

People who play sports can be classified into amateurs (those taking part in an informal, leisure time activity for fewer than 10 hours a week and without a regular calendar of competitive sporting events) and competitive athletes (with regular, scheduled training for more than 10 hours a week; following an official calendar of individual or group competitions, at local, regional, national, or international level). A subgroup in the latter category is made up of professional or elite athletes who pursue constant perfection in competitive sports organized by different national or international sporting leagues or federations [1]. The aims of this paper are to briefly describe a case of SD in a young professional athlete who was treated in our hospital, and to review the literature about sudden death in sports. 


\section{Case Report}

A 16-year-old boy, competing on an elite rowing team, felt dizzy and lost consciousness during a monitored training session. Upon confirming that the boy had no pulse or breathing, his coach immediately proceeded to perform basic cardiopulmonary resuscitation (CPR) until the physicians who were present took over. Within a few minutes, another person present at the scene provided an automatic external defibrillator, and the boy was administered two pulses of 300 Joules. After the second pulse, the boy resumed spontaneous cardiac rhythm and breathing. An ambulance equipped with advanced vital support took him to our hospital's intensive care unit.

The family history included his maternal grandmother, who used a pacemaker from the time she was 39 years old until she experienced SD at age 60, along with his maternal great-grandfather, who also had an SD at age 59. The patient underwent numerous tests, including an electrocardiogram (ECG) on admittance with sinus tachycardia at 114 beats per minute (bpm), a narrow QR interval and a QTc of 441 milliseconds. The epinephrine QT stress test was suggestive of long QT syndrome (LQTS). In the cardiology unit, the boy received a single-chamber implantable automatic defibrillator (IAD), without complications, along with recommendations to continue regular physical exercise but to avoid competitive sports and intense cardiac stress.

\section{Epidemiology}

SD has a low incidence in athletes, ranging from 1:80,000 to 1:200,000 per year [3]. However, the social and mass media impact generates an exaggerated perception of its frequency. The review by Maron published in 2015 [2] reported that more than 30 countries-mostly in Europe and other high-income Western countries-have sudden death registries. The variability seen in registered incidence could be attributable to the type of sport (competitive, recreational, elite), the setting (genetic and/or cultural variations), the type of registry (forensic or hospital records, mass media reports), the time period (year of registration, possibly related to the impact of implementing mandatory medical check-ups prior to participating in some sports, together with recent programs for public access to defibrillators), and the design of the studies (which are mostly retrospective and at risk of selection bias).

The largest registry in the United States is the National Registry of Sudden Death in Athletes, run by the Minneapolis Heart Institute Foundation. Results published in 2014 for a 10-year period (2002 to 2011) in university athletes, ranging in age from 17 to 26 years, showed an incidence of SD of 1.2 to 1.6 events per 100,000 population per year, depending on the cause [4]. Another retrospective study in the United States, with 27 years of follow-up (1980 to 2006), reported an incidence of 0.9 per 100,000 population per year [5].

In Europe, epidemiological data on SD have been published in Norway (incidence 0.9 per 100,000 population per year) and Germany (1.2 per 100,000 popu- 
lation per year) [6] [7].

The epidemiology varies according to factors such as age, sex, and ethnicity [8]. The proportion of incidence between men and women under the age of 35 is $5: 9$, depending on the source of the data, and it ranges from $2.75 \%$ of young women athletes in Italy [9] to $4.95 \%$ in women in the United States [10]. When the registry also considers the population over 35 years of age, the proportion of women rises $8 \%$ of females in the English registry, with ages ranging from 7 to 67 years [11]. With regard to ethnicity, in the United States annual incidence of SD in African American athletes oscillates from 1:3100 to 1:21,400-three times the incidence in white athletes.

There does not appear to be a particular sport that puts athletes at higher risk of SD. The prevalence of different sports in SD registries is directly related to the popularity of the sport in that country. In Spain, the sports that appear most frequently in association to SD are also the most popular: cycling, football (soccer), indoor football, handball, basketball, and track \& field. Football was also the top sport linked to SD in Italy [9]. In the United States, the highest incidence occurred in the most popular university sport: basketball (in 25\% of the cases for unknown reasons, and in $8 \%$, due to hypertrophic cardiomyopathy [HCM]) [12].

Seasonal factors are also at play. Among competitive athletes, SD events occurred most frequently during the autumn and spring and in the early afternoon, while amateurs experienced the most events early in the morning or late in the afternoon, coinciding with the most frequent times of day when people exercise [13].

\section{Etiology, Diagnosis, and Treatment}

Athletes' age and nationality mark certain etiological differences, with variations in the underlying cause of the SD event in each case. Among US athletes, the primary cause of death is HCM, responsible for about $36 \%$ to $37.5 \%$ of the cases [14] [15]. In Italy, AC is the most frequent culprit (22.4\%) [16], and in Ireland it is acute coronary syndrome (ACS), even in athletes under the age of $35(27.2 \%)$ [17]. Among Swedish athletes, congenital anomalies of the coronary arteries (CACA) and HCM each account for $16.7 \%$ of the cases of SD [18], although in a plurality of athletes under the age of 35 in this setting, the cause of death is unknown (31.2\%) [2]. On the other hand, in people aged over 35, the most common cause of SD is ACS (79.3\%) [19].

In the Spanish population, there is not enough available data to accurately determine the most frequent etiologies underlying this phenomenon, in part due to the failure to perform adequate anatomopathological cardiac examination in some athletes and in part to differences in the microscopic diagnostic criteria used [20]. In young ( $<35$ years) Spanish athletes belonging to sports federations, the most frequent cause of SD is AC (21.8\%), followed by LVH (9.3\%), HCM (6.2\%), CACA (6.2\%), ACS (6.2\%), and others (aortic stenosis, conduction disturbances, myocarditis, etc.) [19]. 


\subsection{AC or Arrhythmogenic Right Ventricle Dysplasia (ARVD)}

This disease is characterized by the gradual replacement of the right ventricle myocardium with fibroadipose tissue, which is responsible for the appearance of re-entry circuits. The annual rate of SD in $\mathrm{AC}$ is about $1 \%$ to $3 \%$; the people at the highest risk are those with a history of unexplained fainting (syncope), a family history of SD, onset of symptoms at a young age, and participation in competitive sports. In many cases, the disease has a benign course, with well-tolerated arrhythmias. It presents with ventricular arrhythmias, generally monomorphic ventricular tachycardia with left bundle branch block morphology. It is notable that most cases have a family history of SD (autosomal dominant inheritance with variable penetrance and expression). In the cardiac assessment, some of the structural and functional characteristics of the right ventricle entail significant challenges for diagnosis with transthoracic echocardiography (TTE). In this pathology, the ECG is the key to diagnosis, showing a characteristic pattern with inverted $\mathrm{T}$ waves and prolonged QRS complex with epsilon waves in the right precordial leads.

Treatment includes drugs (the beta-blockers sotalol and/or amiodarone), IAD (the best choice in patients rescued from cardiorespiratory failure, those with poorly tolerated arrhythmias, and patients at high risk), radiofrequency ablation, and heart transplant [20] [21]. Intense physical activity is discouraged [22].

\subsection{Hypertrophic Cardiomyopathy (HCM)}

HCM is a hereditary disease causing an increase in the thickness of the cardiac walls, mainly in the left ventricle, leading to left ventricle hypertrophy (LVH) with no dilation in the cavity. This is the first cause of SD in young people worldwide (including in athletes) without symptoms or a history of cardiac disease [23].

The final mechanism of SD is not fully understood. Different authors have postulated a number of possible causes, including the frequent appearance of both ventricular and supraventricular arrhythmias that produce tachycardia, diastolic dysfunction of the left ventricle, or myocardial ischemia due to a mismatch between the needs of the hypertrophic myocardium and the insufficient degree of vascularization, which moreover undergoes an important systolic compression or a blockage in the left ventricle outflow tract.

The diagnostic approach involves an ECG, a Holter test, and a TTE. The stress test has little value in the diagnostic or prognostic study [23]. The TTE may or may not show an obstruction to the left ventricle outflow tract or the presence of LVH (this could be a normal finding in highly trained athletes, as practicing sport induces adaptive cardiovascular changes (physiological LVH, or so-called "athlete's heart")) [24].

It is difficult to identify which patients are at risk for $\mathrm{SD}$, as there are no established criteria for predicting such an event. Thus, any recommendation regarding physical activity in people with HCM should be conservative. In general, all 
sports are contraindicated, and patients should only participate in activities with low static and dynamic load [23].

Numerous drugs have been tested as prophylaxis for SD in people with HCM, but none have been shown to effectively reduce risk. IADs are the only treatment with a demonstrably high efficacy in preventing SD in high-risk patients. Indications for IADs as primary prevention differ considerably according to country, health system, access to the devices, and different experts' opinions. European authors have stated that the most ominous prognoses are associated with two or more risk factors. Amiodarone is used when the IAD is not available or when the patient refuses its implantation [25].

\subsection{Long QT Syndrome (LQTS)}

LQTS is a heart disease that can be classified within the so-called "channelopathies." The diagnosis of LQTS includes not only the presence of a QT interval of more than 0.44 or 0.45 seconds, but also associated clinical signs (fainting), a family history of SD, and other ECG disturbances (repolarization alterations and arrhythmic episodes). The increase in sympathetic activity associated with physical activity also predisposes people to ventricular fibrillation and syncope. As a result, only moderate physical activity is advised, and participation in intense or competitive sports is prohibited. A diet rich in potassium is also recommended [23].

There is no cure for this disease, and no treatment can restore the QT interval to normal values. However, beta-blockers and/or an IAD (depending on the patient) can help to prevent SD events and notably improve patients' chances for survival [25].

\section{Current Athletic Situation}

In Spain, football, indoor football, basketball, handball, and track \& field are currently the top five competitive sports, so we reviewed the obligation to assess professional or elite athletes in these respective sports federations. We found that although the Spanish Society for Sports Medicine (FEMEDE) has put forward proposals to establish a single standard medical examination for all sports, this measure has not been implemented. Moreover, the Ministry of Education, Culture and Sport approved a sports law in 1990 (Act 10/1990), stipulating that the High Council on Sports could require Spanish sports federations to have athletes undergo medical examinations before granting licenses to participate in official competitions recognized by the state. However, as these mandates have not been formalized to date, each sports federation decides for themselves whether or not to comply with these bodies' recommendations [26].

Thus, some federations, such as the Royal Spanish Federations for Football, Handball, and Track \& Field require all athletes to pass a basic medical exam before receiving a license to compete. These exams consist of a limited and non-standardized medical history and physical examination (at times, the ath- 
letes are not even asked about their family history, nor do they receive an auscultation). Rather, the content of the exam depends on the attending physician, as does the performance of indirect assessments (Ruffier test) to measure aerobic endurance through a short stress test and to assess the capacity for aerobic recovery. Other federations, such as the Spanish Handball Federation, require only members in the top leagues (first tier ACB, second tier LEB Oro, and third tier LEB Plata) to undergo a medical check-up.

However, in the highest tiers of the sports leagues mentioned above, the basic exam is lengthened, with a more detailed anamnesis and physical exam, plus other more specific tests: blood tests, ECG, ergometry, and sometimes even a Holter test or TTE. This more comprehensive assessment depends on each club's interest and economic means.

\section{Current Evidence for Performing Tests}

Various articles have reviewed the available scientific evidence on primary prevention of SD in athletes with the aim of identifying which tests should be performed during the medical exam preceding sporting activity. In Europe, Corrado [27] analyzed the incidence of this problem in young competitive athletes before and after the implementation of a national plan for medical monitoring in Italy. The check-ups became mandatory in 1982 and included a personal and family medical history, a physical examination, and an ECG. In the period preceding these mandatory controls, the incidence of SD was 3.6 events per 100,000 population per year, compared to 0.4 per 100,000 population per year after implementation of the program [27]. Thus, the incidence of SD in young athletes decreased by $89 \%$.

Because the causes of SD are mainly cardiologic [28], in the $36^{\text {th }}$ Bethesda Conference held in New Orleans in 2004 [29], experts recommended taking a careful personal and family history and performing a detailed physical examination to identify possible cardiovascular lesions. However, most young athletes with high-risk diseases are asymptomatic, have normal physical examination results, and show excellent athletic performance. The inclusion of a resting ECG increases the probability of identifying individuals at the highest risk because it shows abnormal values in $95 \%$ and $80 \%$ of people with HCM and AC, respectively. There are also apparent alterations in long and short QT syndromes, Brugada syndrome, and Wolf-Parkinson-White syndrome [30], etiologies that are much less prevalent but show characteristic electrocardiographic alterations. In the United States, Wheeler [31] analyzed the cost-effectiveness of different pre-participation cardiac assessment approaches: no assessment, assessment based on anamnesis and physical examination alone, or extended assessment that also included an ECG. Compared to no assessment, the performance of a basic check-up that included a clinical history and physical examination in a population of 1000 athletes aged 14 to 22 years would save 2.06 life-years at a cost of USD 42,000 per life-year saved. Compared to no intervention, the ex- 
tended assessment would save 2.6 life-years per 1000 athletes, at a cost of USD 76,000 each. We consider that the protocol including the ECG in addition to the clinical history and physical examination is an efficient practice in young athletes, with high sensitivity for the most frequent etiologies (cardiomyopathies). However, the effectiveness of the ECG may vary from one country to another depending on the most frequent cause of sudden cardiac death in each setting.

Considerable controversy exists with regard to performing a TTE in an initial pre-participation examination. Some data support including this test in a screening protocol, as it would enable the detection of some of the most important causes of SD, such as cardiomyopathies, anomalies in the coronary arteries, and conditions affecting the aorta. However, to date no study has been able to demonstrate that this test is cost-effective. Thus, the sensitivity that the TTE would bring to the diagnosis of cardiomyopathies does not seem to add enough value to justify the cost of including it in a mass screening program [32].

\section{Discussion}

Galvanized by a case of SD in a young elite athlete who was treated in our institution after being successfully resuscitated outside our hospital, we have reviewed the data available in the literature with regard to this phenomenon as it relates to sporting activity. In Spain, regulatory laws stop short of mandating pre-participation check-ups, but they do recommend that athletes belonging to national sports federations undergo a standard medical examination. Many papers indicate that one of the biggest challenges in diagnosing heart disease in these athletes lies in the interpretation of the ECG that the attending physician performs. A certain level of specialized expertise is necessary to detect and differentiate normal physiological patterns in athletes (athlete's heart) from pathological patterns. To optimize ECG readings in sports medicine, we recommend implementing professional training for interpreting ECG patterns in athletes.

In the area of secondary prevention, Marijon [33] highlighted the most important predictors for surviving an SD event in the hospital after first response in the community: having promptly received CPR and defibrillation. Thus, we would also propose the development and implementation of policies targeted to increasing the availability of defibrillators in sports facilities, raising awareness around their use, and educating and training the sports community in basic CPR maneuvers and the use of defibrillation.

We have observed that the etiology of SD varies by geographical location. In Spain, the main causes of this event are consistent with those reported in Italy [34]. That country successfully achieved an $89 \%$ decrease in incidence among athletes after establishing pre-participation medical check-ups that included anamnesis, physical examination and ECG. Thus, we believe that this protocol is feasible to implement on a general level in other countries as well. We underline that the target population would be under 35 years of age, when SD entails a larger impact on potential years of life lost. 


\section{Conclusion}

In summary, we propose: 1) a pre-participation medical check-up for all competitive athletes as a pre-condition to their registration in nationally recognized sporting events. The check-up would include the completion of the sports medicine clinical history (Annex); 2) the performance of a basic physical examination, assessing key medical indicators (anthropometry: weight, height, body mass index; inspection, palpation, and auscultation of the lungs and abdomen; evaluation of the locomotor apparatus and nervous system) as well as a cardiologic exam (cardiac and carotid auscultation, central and peripheral pulse, determination of heart rate at rest and following a short stress test, and blood pressure reading); and finally, 3) performance of a 12-lead resting ECG. If this test shows altered electrocardiographic patterns, additional investigations by a cardiologist are warranted (TTE and ergometry). Thus, it is essential to have an individual assessment from a physician specialized in sports medicine and/or cardiology, as well as additional tests if the standard anamnesis and physical examination yield abnormal results. Identifying people at high risk would enable the medical community to persuasively discourage them from participating in sports, thereby reducing their risk and preventing new cases of SD.

\section{Description of Authors' Roles}

M.E. Caparrós, M. García, C. Miró, M. del Mar Ponce, A. Ruso and J.M. Seguí designed the study and supervised the data collection. J. Méndez, F. Caparrós and J.M. Seguí wrote the paper. M.E. Caparrós, M. García, C. Miró, M. del Mar Ponce, A. Ruso, C. García, Ma D. Jover, C. Seguí, A. Pérez, P. Esteve, D. Bonet, J. Peris, M. Seguí, and P. Roig collected the data and assisted with writing the article.

\section{Conflicts of Interest}

None of the authors have personal conflict of interest nor have they received payments for the performance of this work.

\section{References}

[1] Solberg, E.E., Borjesson, M., Sharma, S., et al. (2016) Sport Cardiology Section of the EACPR of the ESC. Sudden Cardiac Arrest in Sports Need for Uniform Registration: A Position Paper from the Sport Cardiology Section of the European Association for Ardiovascular Prevention and Rehabilitation. Eur J Prev Cardiol., 23, 657-667.

[2] Suárez-Mier, M.P. and Aguilera, B. (2002) Causas de muerte súbita asociada al deporte en España. Rev Esp Cardiol., 55, 347-358.

[3] Maron, B.J. (2015) Historical Perspectives on Sudden Deaths in Young Athletes with Evolution over 35 Years. The American Journal of Cardiology, 116, 1461-1468. https://doi.org/10.1016/j.amjcard.2015.07.072

[4] Maron, B.J., Haas, T.S., Murphy, C.J., et al. (2014) Incidence and Causes of Sudden Death in U.S. College Athletes. Journal of American College of Cardiology, 63, 
1636-1643.

[5] Maron, B.J., Doerer, J.J., Haas, T.S., Tierney, D.M. and Mueller, F.O. (2009) Sudden Deaths in Young Competitive Athletes: Analysis of 1866 Deaths in the United States, 1980-2006. Circulation, 119, 1085-1092. https://doi.org/10.1161/CIRCULATIONAHA.108.804617

[6] Solberg, E.E., Gjertsen, F., Haugstad, E., et al. (2010) Sudden Death in Sports among Young Adults in Norway. European Journal of Cardiovascular Prevention and Rehabilitation, 17, 337-341.

[7] Bohm, P., Scharhag, J. and Meyer, T. (2016) Data from a Nationwide Registry on Sports-Related Sudden Cardiac Deaths in Germany. European Journal of Preventive Cardiology, 23, 649-656.

[8] Chugh, S.S. and Weiss, J.B. (2015) Sudden Cardiac Death in the Older Athlete. Journal of the American College of Cardiology, 65, 493-502. https://doi.org/10.1016/j.jacc.2014.10.064

[9] Corrado, D., Basso, C., Rizzoli, G., et al. (2003) Does Sports Activity Enhance the Risk of Sudden Death in Adolescents and Young Adults? Journal of the American College of Cardiology, 42, 1959-1963. https://doi.org/10.1016/j.jacc.2003.03.002

[10] Harmon, K.G., Asif, I.M., Klossner, D., et al. (2011) Incidence of Sudden Cardiac Death in National Collegiate Athletic Association Athletes. Circulation, 123, 1594-1600. https://doi.org/10.1161/CIRCULATIONAHA.110.004622

[11] Finocchiaro, G., Papadakis, M., Robertus, J.L., et al. (2016) Etiology of Sudden Death in Sports: Insights from a United Kingdom Regional Registry. Journal of American College of Cardiology, 67, 2108-2115.

[12] Harmon, K.G., Asif, I.M., Maleszewski, J.J., et al. (2015) Incidence, Cause, and Comparative Frequency of Sudden Cardiac Death in National Collegiate Athletic Association Athletes: A Decade in Review. Circulation, 132, 10-19. https://doi.org/10.1161/CIRCULATIONAHA.115.015431

[13] Maron, B.J., Shirani, J., Poliac, L.C., Mathenge, R., Roberts, W.C. and Mueller, F.O. (1996) Sudden Death in Young Competitive Athletes Clinical, Demographic and Pathological Profiles. JAMA, 276, 199-204. https://doi.org/10.1001/jama.1996.03540030033028

[14] Maron, B.J., Shirani, J., Poliac, L.C., Mathenge, R., Roberts, W.C. and Mueller, F.O. (1996) Sudden Death in Young Competitive Athletes. Clinical, Demographic and Pathological Profiles. JAMA, 276, 199-204. https://doi.org/10.1001/jama.1996.03540030033028

[15] Van Camp, S.P., Bloor, C.M., Mueller, F.O., Cantu, R.C. and Olson, H.G. (1995) Nontraumatic Sports Death in High School and College Athletes. Medicine \& Science in Sports \& Exercise, 27, 641-647.

[16] Weslen, L., Pahlson, C. and Lindquist, O. (1996) An Increase in Sudden Unexpected Cardiac Deaths among Young Swedish Orienteers during 1979-92. European Heart Journal, 17, 902-910. https://doi.org/10.1093/oxfordjournals.eurheartj.a014972

[17] Bux, R., Parzeller, M., Raschka, C. and Bratzke, H. (2004) Early Symptoms and Causes Sudden Death Related to Sports Activities. Deutsche Medizinische Wochenschrift, 129, 997-1001.

[18] Corrado, D., Basso, C., Schiavon, M. and Thiene, G. (1998) Screening for Hypertrophic Cardiomyopathy in Young Athletes. The New England Journal of Medicine, 339, 364-369. https://doi.org/10.1056/NEJM199808063390602

[19] Basso, C., Burke, M., Fornes, P., Gallagher, P.J., De Gouveia, R.H., Sheppard, M., et 
al. (2008) Guidelines for Autopsy Investigation of Sudden Cardiac Death. Virchows Archiv, 452, 11-18. https://doi.org/10.1007/s00428-007-0505-5

[20] Tomé Esteban, M.T., García-Pinilla, J.M. and McKenna, W.J. (2004) Actualización en miocardiopatía arritmogénica del ventrículo derecho: Genética, diagnóstico, manifestaciones clínicas y estratificación de riesgo. Revista Española de Cardiología, 57, 757-767.

[21] Albina, G., Laíño, R. and Giniger, A. (2009) Displasia arritmogénica del ventrículo derecho: Revisión de una enfermedad poco común con un espectro variado de presentaciones clínicas. Revista Electrofisiología y Arritmias, 2, 139-144.

[22] Marcus, F.I., Fontaine, G.H., Frank, R., Gallagher, J.J. and Reiters, M.J. (1989) Long-Term Follow-Up in Patients with Arrhythmogenic Right Ventricular Disease. European Heart Journal, 10, 68-73.

[23] Pérez, A., Rodrigo, A., Berrazueta, J., Alcaine, R., Fernández, E., Marqueta, P., Pons, C. and Beristain, I. (2000) Guías de práctica clínica de la Sociedad Española de Cardiología sobre la actividad física en el cardiópata. Revista Española de Cardiología, 53, 684-726. https://doi.org/10.1016/S0300-8932(00)75145-1

[24] Epstein, A.E., DiMarco, J.P., Ellenbogen, K.A., Estes, N.A. 3rd, Freedman, R.A., Gettes, L.S., et al. (2008) ACC/AHA/HRS 2008 Guidelines for Devicebased Therapy of Cardiac Abnormalities. Circulation, 117, 350-408.

[25] Muñoz-Esparza, C., García-Molina, E., Salar-Alcaraz, M., Peñafiel-Verdú, P., Sánchez-Muñoz, J.J., Martínez Sánchez, J., Cabañas-Perianes, V., Valdés Chávarri, M., García Alberola, A. and Gimeno-Blanes, J.R. (2015) Heterogeneous Phenotype of Long QT Syndrome Caused by the KCNH2-H562R Mutation: Importance of Familial Genetic Testing. Revista Española de Cardiología, 68, 861-868. https://doi.org/10.1016/j.rec.2014.10.022

[26] Bilbao, A., Jiménez, L., López, J., Manonelles, P. and Pérez, A. (2009) Sistema de Reconocimientos Médicos para la Práctica del Deporte. Reconocimientos Médico-Deportivos, 1-64.

[27] Corrado, D., Basso, C., Pavei, A., et al. (2006) Trends in Sudden Cardiovascular Death in Young Competitive Athletes after Implementation of a Preparticipation Screening Program. JAMA, 296, 1593-1601. https://doi.org/10.1001/jama.296.13.1593

[28] Boraita, A. (2011) La muerte súbita del deportista. Revista Española de Medicina Legal, 37, 146-154. https://doi.org/10.1016/S0377-4732(11)70081-5

[29] Maron, B.J., Douglas, P.S., Nishimura, R.A., Graham, T.P. and Thompson, P.D. (2005) 36th Bethesda Conference. Task Force 1: Pre-Participation Screening and Diagnosis of Cardiovascular Disease in Athletes. Journal of the American College of Cardiology, 45, 1312-1375.

[30] Corrado, D., Pelliccia, A., Bjørnstad, H.H., Vanhees, L., Biffi, A., Borjesson, M., et al. (2005) Cardiovascular Pre-Participation Screening of Young Competitive Athletes for Prevention of Sudden Death: Proposal for a Common European Protocol. European Heart Journal, 26, 516-524. https://doi.org/10.1093/eurheartj/ehi108

[31] Weeler, M.T., Heidenreich, P.A., Froelicher, V.F., Hlatky, M.A. and Ashley, E.A. (2010) Cost-Effectiveness of Pre-Participation Screening for Prevention of Sudden Death in Young Athletes. Annals of Internal Medicine, 152, 276-286. https://doi.org/10.7326/0003-4819-152-5-201003020-00005

[32] Grazioli, G., Merino, B., Montserrat, S., Vidal, B., Azqueta, M., Pare, C., et al. (2014) Utilidad del ecocardiograma en la revisión preparticipativa de deportistas de competición. Revista Española de Cardiología, 67, 701-705. 
https://doi.org/10.1016/j.recesp.2013.11.023

[33] Marijon, E., Tafflet, M., Celermajer, D.S., Dumas, F., Perier, M.D., Mustafic, H., et al. (2011) Sports-Related Sudden Death in General Population. Circulation, 124, 672-681. https://doi.org/10.1161/CIRCULATIONAHA.110.008979

[34] Boraita, A. (2002) Muerte súbita y deporte. Hay alguna manera de prevenirla en los deportistas? Revista Española de Cardiología, 55, 333-336.

https://doi.org/10.1016/S0300-8932(02)76610-4 


\section{Annex}

Sports medicine anamnesis questionnaire for medical check-up, conditional for obtaining competition license.

The questionnaire should be accompanied by medical reports that can provide information on the athlete's health status.

Personal information:

\begin{tabular}{lll}
\hline Name and surname: & Date of birth: & Place of birth: \\
Sex: & Street address: & City (Province): \\
Zip code: & Country: & National ID number: \\
Race/ethnicity: & Nationality: & \\
Telephone: & Email: & \\
\hline
\end{tabular}

Sports information:

Federation:
Competitive level achieved:

Mark your answer to the following questions with an X. Please, specify if you answer "yes".

Do you have any current or chronic illnesses (including high blood pressure, diabetes, or high cholesterol? Yes:

No:

Do you have any allergies (incl. seasonal allergies)?

Yes:

No:

Have you ever had surgery or a blood transfusion?

Yes:

No:

Are you currently on any medication or taking any pills (including supplements or vitamins to gain/lose weight or improve your performance)?

Yes:

No:

Have you ever felt dizzy, had chest pain, or fainted during or after exercise?

Yes:

No:

Have you ever felt your heart rate speed up more than normal or thought that it skipped a beat? 
Yes:

No:

Have you ever been told that you had a heart murmur?

Yes:

No:

Do you have any family members with high blood pressure or diabetes?

Yes:

No:

Has anyone in your family ever had heart disease or died suddenly due to heart problems, and if so, how old were they?

Yes (age): (years)

No:

Have you ever had a major viral infection like pericarditis, myocarditis, mononucleosis, or something similar?

Yes:

No:

Has a doctor ever discouraged or recommended limiting your sports activity for any reason?

Yes:

No:

Have you ever had a concussion or head injury?

Yes:

No:

Have you ever lost consciousness and/or memory?

Yes:

No:

Have you ever had a seizure?

Yes:

No:

Have you ever felt numbness, tingling, burning, or stinging in your arms or legs?

Yes:

No:

Have you ever experienced problems when exercising in a hot environment? Yes:

No:

Have you ever had a cough, wheezing or breathing problems during or following exercise?

Yes:

No:

Do you regularly use tobacco, drink alcohol or take drugs?

Yes:

No: 